\title{
A prospective comparison of 'conventional' and high carbohydrate / high fibre / low fat diets in adults with established Type 1 (insulin-dependent) diabetes
}

\author{
D. K. McCulloch*, R.D. Mitchell, J.Ambler and R. B. Tattersall \\ University Hospital, Queens Medical Centre, Nottingham, UK
}

\begin{abstract}
Summary. Diabetic associations throughout the world are recommending high carbohydrate / high fibre / low fat diets for diabetic patients as a means of improving general health and metabolic control. We have previously shown that the efficacy of a 'conventional' low carbohydrate diet can be greatly increased by improving the method of dietary education. To test whether further improvement in metabolic control could be achieved by changing to a high carbohydrate / high fibre / low fat diet we have followed a group of 40 Type 1 (insulin dependent) diabetic adults for up to 19 months. They had all been prescribed a conventional low carbohydrate diet taught by one of three methods (dietician only, practical lunchtime demonstration or videotape). Those taught by dietician only were left as a control group for follow-up (group A). The others were randomized either to continue on their present diet (group B) or to change to a high carbohydrate / high fibre / low fat diet (group C). At final assessment those in groups B
\end{abstract}

and $\mathrm{C}$ were more knowledgeable, compliant and better controlled than group $\mathrm{A}$. Those in group $\mathrm{C}$ achieved a change from $38 \%$ carbohydrate $/ 43 \%$ fat $/ 20 \mathrm{~g}$ fibre daily to $45 \%$ carbohydrate / $34 \%$ fat / $32 \mathrm{~g}$ fibre daily. However, metabolic control in group $\mathrm{C}$ deteriorated while taking the high carbohydrate / high fibre / low fat diet (haemoglobin $\mathrm{A}_{1}$ went from $9.4 \pm 0.5 \%$ to $11.2 \pm 0.5 \%, p<0.01$, over 4 months). None of the patients in group $\mathrm{C}$ changed their eating habits or those of their families nearly as much as was recommended. This study suggests that imaginative and practical teaching methods are the most important factor influencing dietary compliance and metabolic control in Type 1 diabetic adults and that no additional improvement is achieved in this group by changing to a high carbohydrate / high fibre / low fat diet.

Key words: Insulin-dependent diabetes, metabolic control, high carbohydrate / high fibre diet, education.
No diet, however, beneficial in theory, will work unless it is eaten; in the treatment of diabetes the gulf between what is prescribed and what is consumed is very wide [1-4]. We have previously shown an improvement in dietary compliance and metabolic control in a group of adults with longstanding poorly controlled Type 1 diabetes when imaginative teaching methods were introduced, even though the diet was a conventional low carbohydrate one [5]. In this study we have followed the same group of patients for a further 6-10 months to answer the following questions: will the improved knowledge, compliance and metabolic control shown previously [5] be maintained after stopping formal education? Will these patients obtain further benefit by changing to a more modern diet containing less fat and more high fibre carbohydrate, as suggested by most National Diabetes Associations? How well do patients and their families respond to the high fibre / low fat diet?

\footnotetext{
* Present appointment: Diabetes Research Fellow, University of Washington, Seattle, Washington 98195, USA
}

\section{Subjects and methods}

Forty Type 1 diabetic patients (mean age 35 years, range 17-64 years) completed the first part of the study [5] the design of which is shown in Figure 1. During the initial run-in period ( $0-3$ months), an attempt was made to improve overall diabetic treatment and metabolic control without mentioning diet. The value of long-term normoglycaemia was stressed and patients were told how this could be assessed by regular home blood glucose recordings and laboratory estimations of haemoglobin $\mathrm{A}_{1}\left(\mathrm{HbA}_{1}\right)$. Capillary blood glucose concentrations were measured before each meal and before bed on 2 days a week using visually read test strips (BM test, Glycemie 20-800 strips, Boehringer Mannheim). On one day per week they were asked to check the blood glucose at $3 \mathrm{a} . \mathrm{m}$. They were set a target of achieving and maintaining blood glucose values of $4-8 \mathrm{mmol} / 1$. No change was made to the species or purity of insulin preparation being used, but all were changed to a regimen of short and intermediate acting insulin given $30 \mathrm{~min}$ before breakfast and $30 \mathrm{~min}$ before the evening meal. They were taught to adjust their own insulin doses using the following guidelines. The morning short acting insulin was adjusted on the basis of before lunchtime blood glucose results. Every 8-10 days the average glucose was calculated. If this was above $8 \mathrm{mmol} / 1$ then the morning short acting insulin was increased by 4 units. If the average was below $4 \mathrm{mmol} / 1$ or if there had been any documented episodes of midmorning hypoglycaemia then the morning short acting insulin was reduced 


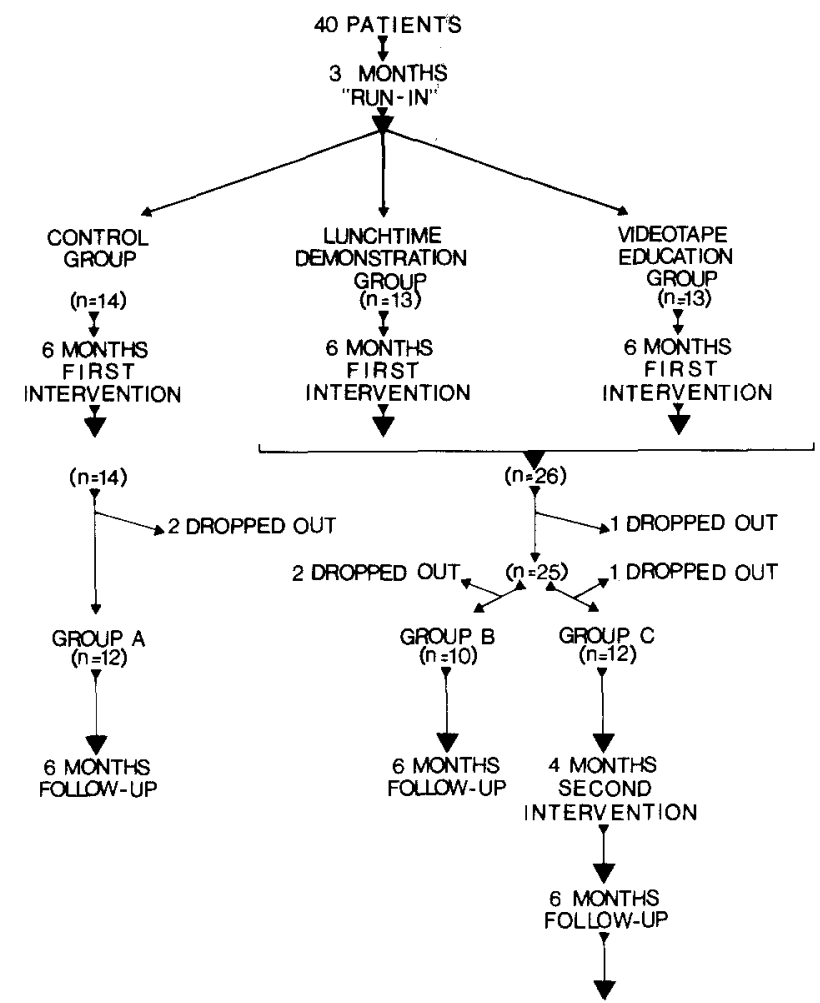

Fig. 1. Flow diagram showing the overall study design and where patients dropped out of the study

Table 1. Clinical characteristics of patients in the study

\begin{tabular}{llll}
\hline & $\begin{array}{l}\text { Group A } \\
(n=12)\end{array}$ & $\begin{array}{l}\text { Group B } \\
(n=10)\end{array}$ & $\begin{array}{l}\text { Group C } \\
(n=12)\end{array}$ \\
\hline Men & 7 & 5 & 7 \\
Women & 5 & 5 & 5 \\
Age (years) & $38.1 \pm 2.6$ & $29.8 \pm 2.8$ & $39.3 \pm 3.9$ \\
$\begin{array}{l}\text { Duration of diabetes } \\
\quad(\text { years })\end{array}$ & $11.5 \pm 1.8$ & $11.6 \pm 1.3$ & $14.3 \pm 1.8$ \\
$\begin{array}{l}\text { Insulin dose } \\
\quad\left(\mathrm{U} \cdot \mathrm{kg}^{-1} \cdot \text { day }^{-1}\right)\end{array}$ & $0.67 \pm 0.07$ & $0.88 \pm 0.08$ & $0.67 \pm 0.03$ \\
$\begin{array}{l}\text { Initial HbA } \\
\text { Body mass index }\end{array}$ & $13.1 \pm 0.5$ & $12.0 \pm 0.6$ & $12.9 \pm 0.5$ \\
$\quad\left(\mathrm{~kg} / \mathrm{m}^{2}\right)$ & $24.4 \pm 0.8$ & $23.2 \pm 0.8$ & $24.3 \pm 0.5$ \\
\hline
\end{tabular}

Results expressed as mean \pm SEM

by 4 units. The blood glucose results before the evening meal were used to adjust the morning intermediate acting insulin, the before bedtime tests were used for the before evening meal short acting insulin. For adjustment of the intermediate acting insulin before the evening meal attention was paid to both the $3 \mathrm{a} . \mathrm{m}$. and before breakfast glucose values. If, by increasing this insulin dose, it was not possible to keep the before breakfast glucose below $8 \mathrm{mmol} / 1$ without causing nocturnal hypoglycaemia ( $3 \mathrm{a} . \mathrm{m}$. glucose $<4 \mathrm{mmol} / \mathrm{l}$ ) then the evening insulin was split such that only short acting insulin was given before the evening meal with the intermediate acting insulin given at 9 p. m. Patients were seen at monthly intervals and contacted by telephone between visits during the run-in to verify their competence at insulin self-adjustment. They were told their $\mathrm{HbA}_{1}$ result at each visit and it was stressed that the aim was to keep this below $10 \%$. These targets and methods of monitoring were continued throughout the study.

At the end of the run-in period patients were randomized to one of three methods of dietary teaching: individual tuition from a dietician
( $n=14)$, small group teaching using a videotape $(n=13)$ or practical lunchtime demonstrations $(n=13)$. The dietary policy and educational methods during this first intervention period have been described in detail elsewhere [5]. The dietary policy was the same for all three groups and was kept simple with the types of food eaten determined largely by patient preference. What was particularly stressed was that each patient should learn to judge how much carbohydrate they ate at each meal and snack and that this should be kept consistent from dayto-day. Each group was seen three times for dietary education during the intervention period.

At the end of the first intervention period, all patients were asked whether they would be prepared to continue for a further 6-10 months. Three refused; two in the control group insisted that they now see the video tape, while one from the lunchtime demonstration group was unwilling to take more time off work. This left 12 in the control group (group A, Fig. 1). The remaining 25 patients, who had received either lunchtime demonstrations or video tape education, were then randomized either to continue their current diet with a review in 6 months (group $\mathrm{B}, n=12$ ) or to undertake a second intervention period where their diet was changed to a high carbohydrate / high fibre / low fat diet (group C, $n=13$ ). This second intervention period was to last 4 months with a final assessment 6 months later (i.e. 10 months after randomization). During the last 6-month period patients were neither seen nor given dietary advice unless they had a specific query. One patient in group $\mathrm{C}$ dropped out because he moved from the area and two in group B defaulted for their final visit. Thus the final groupings were: group A - 12 patients, group B - 10 patients, group $\mathrm{C}-12$ patients.

Clinical details of the patients are shown in Table 1. Those in group $\mathrm{B}$ are younger, have a higher insulin dose and slightly lower $\mathrm{HbA}_{1}$ than groups $\mathrm{A}$ and $\mathrm{C}$, but none of the differences was statistically significant (Mann-Whitney U test $p>0.1$ ).

\section{Dietary policy during the second intervention period}

The principle of maintaining a consistent carbohydrate profile from day-to-day was continued, but patients were also told that the new objective was to alter the content of the diet in accordance with the British Diabetic Association's "dietary recommendations for diabetics in the 1980's" [6]. Energy intake was assessed from 7-day food records and a carbohydrate allowance prescribed to provide approximately $50 \%$ of energy from carbohydrate. Special care was taken to explain that, as the carbohydrate allowance had been increased, fat intake must be reduced to precent an increase in calories and body weight. The use of low fat spreads, skimmed and semi-skimmed milk, cottage cheese, white fish and poultry were encouraged. In accordance with the recommendations of the British Diabetic Association [6], it was suggested that most carbohydrate should be eaten as polysaccharides, particularly fibre-rich unprocessed foods such as wholemeal bread, crisp breads, wholemeal flour and pasta, whole grain breakfast cereals and brown rice. It was also suggested that vegetables and fruit should be eaten liberally at both midday and evening meals.

The advantages of pulses (such as beans and lentils) were stressed and suggestions made as to how dried and canned pulses could be incorporated into meals. The educational method used during the second intervention period was similar to the practical lunchtime demonstrations which had proved so successful during the first intervention [5]. Patients were seen in small groups with their spouse where possible. In addition to printed instructions they were given two recipe books, "Better cookery for diabetics" [7] and "The diabetic's diet book" [8]. To encourage the use of high fibre / low fat foods, a selection of these was on display at each dietetic appointment, 1, 2 and 4 months after initial instructions. Several recipes contained in the two books $[7,8]$ were prepared by the dietician so that patients and their families could sample these and discuss practical problems at each visit. During the last visit patients were given a questionnaire about the palatability and acceptability of the new diet. At the end of the second intervention period, patients in group $C$ were asked to continue the same diet and were seen for final follow-up 6 months later. As with groups A and B no new dietary advice or teaching was given during the final 6 months unless specifically requested. 
Table 2. Changes within three groups of Type 1 diabetic adults in dietary knowledge and dietary compliance at the end of the run-in (Initial), at the end of the first intervention period (Middle) and at the end of the study (Final)

\begin{tabular}{|c|c|c|c|}
\hline & $\begin{array}{l}\text { Group A } \\
(n=12)\end{array}$ & $\begin{array}{l}\text { Group B } \\
(n=10)\end{array}$ & $\begin{array}{l}\text { Group C } \\
(n=12)\end{array}$ \\
\hline \multicolumn{4}{|c|}{$\begin{array}{l}\text { Questionnaire score } \\
\quad(\text { maximum possible }=20)\end{array}$} \\
\hline Initial & $11.1 \pm 1.0$ & $11.3 \pm 0.9$ & $11.5 \pm 1.0$ \\
\hline Middle & $8.9 \pm 1.1$ & $17.6 \pm 0.5^{\mathrm{a}}$ & $16.7 \pm 0.8^{\mathrm{a}}$ \\
\hline Final & $11.5 \pm 1.6$ & $17.8 \pm 0.8^{b}$ & $17.6 \pm 0.8^{b}$ \\
\hline \multicolumn{4}{|c|}{$\begin{array}{l}\text { Dietary compliance } \\
\text { overall coefficient of } \\
\text { variation }(\%)\end{array}$} \\
\hline Initial & $51.8 \pm 5.8$ & $64.6 \pm 9.8$ & $46.6 \pm 6.6$ \\
\hline Middle & $53.1 \pm 8.4$ & $29.3 \pm 6.7^{b}$ & $31.0 \pm 4.9^{\mathrm{b}}$ \\
\hline Final & $50.0 \pm 7.0$ & $28.1 \pm 11.7^{\mathrm{b}}$ & $29.8 \pm 6.7^{b}$ \\
\hline
\end{tabular}

Results expressed as mean \pm SEM. An a indicates $p<0.01$ and $\mathrm{b}$ indicates $p<0.001$ when compared with group A using Mann-Whitney U-test

\section{Assessment of dietary knowledge, compliance and content}

Dietary knowledge was tested by three questionnaires, one at the end of the run-in, one at the end of the first intervention period and one at the very end of the study. The questions were similar but not identical and tested the patient's understanding of his or her own diet. They were asked how many $10 \mathrm{~g}$ carbohydrate exchanges they ate each day and what steps they took to ensure accurate measurement. Finally, they were asked specific questions about the number of $10-\mathrm{g}$ carbohydrate exchanges contained in several common foods including items in their own exhange lists. The maximum score on each questionnaire was 20 points.

Dietary compliance was assessed from detailed 7-day food records. These were taken at the end of the run-in, at the end of the first intervention period and at the end of the study. Group $\mathrm{C}$ completed an additional food record at the end of the second intervention period to measure consistency of carbohydrate intake. The data derived from the food records were handled as follows; the amount of carbohydrate taken at each of the seven breakfasts was calculated. The coefficient of variation was then derived (SD/mean $\times 100)$. This calculation was repeated for all meals and snacks. In this way six coefficients of variation were derived from each food record - one for each meal and snack. An average was then calculated to give a single figure, the overall coefficient of variation for each 7-day food record which is a measure of day-to-day consistency in carbohydrate intake.

Dietary content was calculated from food records to give the average daily calorie intake, the percentage of calorie intake derived from carbohydrate, fat and protein and the daily fibre intake.

Metabolic control was assessed by serial $\mathrm{HbA}_{1}$ measurements using an electrophoretic method on cellulose acetate membranes [9]. The coefficient of variation for this method is $<6 \%$ where $\mathrm{HbA}_{1}$ is $<$ $10 \%$ of total Haemoglobin $\mathrm{A}$ and is $<4 \%$ where $\mathrm{HbA}_{1}$ is $>14 \%$ of total Haemoglobin A. Samples were measured in duplicate and $\mathrm{HbA}_{1}$ control (Glycophore product no.51262, Gelman Sciences, UK) run on each membrane. Where duplicate samples differed by $>1 \%$ the analysis was repeated.

\section{Statistical analysis}

Paired non-parametric statistical tests were used. Progressive changes within each group were tested by the Wilcoxon matched sign rank test while comparisons between groups were tested with the Mann-Whitney method. Results are expressed as mean \pm SEM.

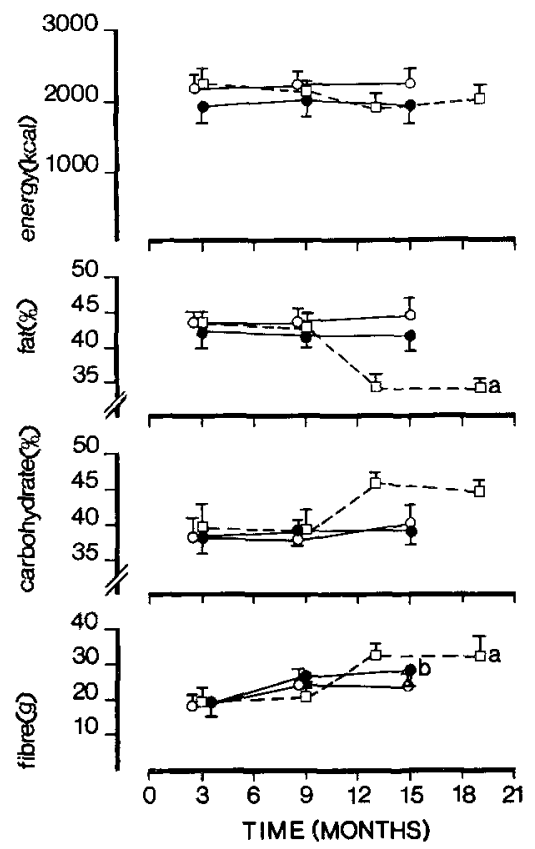

Fig. 2. Changes in calorie intake (kcal), fat and carbohydrate (expressed as percentage of daily $\mathrm{kcal}$ ) and fibre ( $\mathrm{g} / \mathrm{day}$ ) in group $\mathrm{A}$ $(\mathrm{O}-\mathrm{O})$, group B $(-\mathrm{O})$ and group $\mathrm{C}(\square--\square)$ throughout the study. An a indicates $p<0.02$ and $\mathrm{b}$ indicates $p<0.05$ when compared with group $A$. Results are expressed as mean \pm SEM

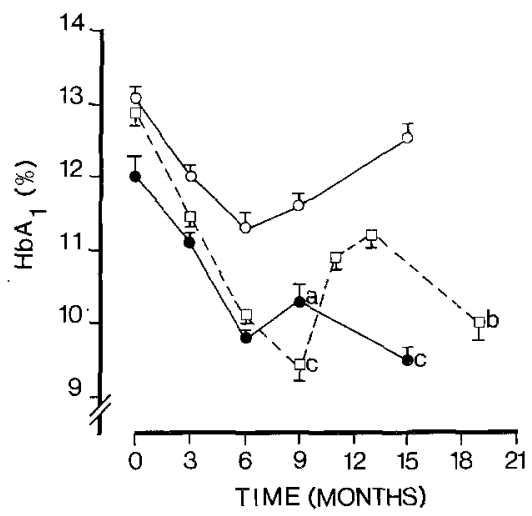

Fig. 3. Changes in $\mathrm{HbA}_{1}$ in groups $\mathrm{A}, \mathrm{B}$ and $\mathrm{C}$ throughout the study. An a indicates $p<0.05$, $\mathrm{b}$ indicates $p<0.02$ and $\mathrm{c}$ indicates $p<0.002$ when compared with group A

Table 3. Changes in types of food eaten by patients in group $\mathrm{C}$ $(n=12)$ at the end of the second intervention period compared with the end of the first intervention

\begin{tabular}{llllll}
\hline & Never & $\begin{array}{l}\text { Less } \\
\text { often }\end{array}$ & $\begin{array}{l}\text { No } \\
\text { change }\end{array}$ & $\begin{array}{l}\text { More } \\
\text { often }\end{array}$ & Always \\
\hline White bread & 5 & 7 & & & \\
Wholemeal bread & & & & 7 & 5 \\
High fibre biscuits & & & 5 & 4 & 3 \\
Bran cereals & & & 1 & 5 & 6 \\
Pulses (lentils, beans) & & & 8 & 4 & \\
Butter & 7 & 3 & 2 & & \\
Margarine & 9 & 1 & 2 & & 6 \\
Low fat spread & 2 & & & 4 & 4 \\
Skimmed milk & 2 & & 2 & 4 & 4 \\
Cheese & & 9 & 3 & & \\
Fried food & 2 & 5 & 5 & & \\
Fruit & & & 10 & 2 & \\
\hline
\end{tabular}




\section{Results}

Daily insulin dose and body mass index did not change significantly within or between groups throughout the study.

Dietary knowledge was equally poor in all three groups at the beginning of the study with an average score of only $55 \%$ (Table 2). No improvement was seen in the control subjects at any stage, whereas both groups $\mathrm{B}$ and $\mathrm{C}$ showed a significant improvement in knowledge after the first intervention period (Wilcoxon matched sign rank test $p<0.01$ ) which was maintained in both groups 12-16 months later. Groups B and C knew significantly more than group A after the first intervention period $(p<0.001)$ and at the end of the study $(p<0.01)$, but did not differ significantly from one another with both answering over $85 \%$ of questions correctly at the end of the study.

Consistency of carbohydrate intake from day-today was equally erratic in all three groups at the outset with an overall coefficient of variation between 46 and $65 \%$. There was no significant change in group A at any stage, but groups $\mathrm{B}$ and $\mathrm{C}$ became significantly more consistent both at the end of the first intervention period $(p<0.01)$ and at the end of the study $(p<0.01)$.

Daily calorie intake did not differ between the groups at the start being $2267 \pm 152 \mathrm{kcal}$ for group A, $1829 \pm 140 \mathrm{kcal}$ for group B and $2233 \pm 163 \mathrm{kcal}$ for group $\mathrm{C}$. There was no significant change in calorie intake either within or between groups throughout the study as would be expected from the lack of change in body weight. Daily fat consumption (expressed as a percentage of daily calorie intake) did not change significantly in groups $\mathrm{A}$ and $\mathrm{B}$ throughout the study. However, during the second intervention period, group $\mathrm{C}$, as expected after instruction in a low fat diet, showed a significant reduction in fat intake from $42.6 \pm 1.9 \%$ to $33.9 \pm 1.7 \%(p<0.01$, Fig. 2$)$. This reduction was maintained for a further 6 months and at final follow-up group $C$ were still eating significantly less fat than groups A or B $(p<0.02)$. The opposite trend was seen with carbohydrate intake (Fig. 2). There was no change in groups $\mathrm{A}$ and $\mathrm{B}$ but group $\mathrm{C}$ increased their intake from $38.8 \pm 1.6 \%$ of total calories to $45.4 \pm 1.3 \%(p<$ 0.01 ) during the second intervention period. However, at final follow-up the difference in carbohydrate intake between the groups was not significant, although group C patients were still taking nearly $45 \%$ of their total intake as carbohydrate.

Daily fibre intake was $<20 \mathrm{~g}$ in all groups at the start of the study and did not change in group A. In group C there was a significant increase in fibre intake from $20.3 \pm 1.6 \mathrm{~g}$ to $31.8 \pm 1.7 \mathrm{~g}(p<0.01)$ during the second intervention period and this was maintained so that at final follow-up it remained significantly higher than in group $\mathrm{A}(p<0.02)$. What was surprising was that patients in group B who had not received specific advice about increasing fibre intake, did show a steady in- crease so that at final follow-up their intake of $28.5 \pm$ $3.0 \mathrm{~g}$ daily was significantly greater than group A $(p<$ 0.05 ) and not significantly different from group $\mathrm{C}$.

The extent to which patients in group $\mathrm{C}$ actually altered their dietary content is shown in Table 3. Most patients found it easy to change from white to wholemeal bread and from butter to low-fat spread. However, we were less successful in persuading them to reduce the amount of cheese and fried food. In addition, only four of the twelve increased the amount of pulses in their diet. Interestingly, of the five who were troubled by "wind", four were the ones who had tried to increase their consumption of pulses.

Overall, four patients in group $\mathrm{C}$ found the high fibre diet more enjoyable, three less enjoyable and five expressed no preference. Only five of the twelve managed to persuade anyone else in the family to adopt the new diet. Seven made some effort to read the recipe books, but only two had actually tried more than three of the recipes.

Diabetic control was equally poor in all three groups at the start of the study (Fig. 3) and improved to a similar degree by the end of the run-in period when $\mathrm{HbA}_{1}$ levels were $12.0 \pm 0.3 \%, 11.1 \pm 0.6 \%$ and $11.4 \pm$ $0.5 \%$ respectively in groups $\mathrm{A}, \mathrm{B}$ and $\mathrm{C}$. During the first intervention period $\mathrm{HbA}_{1}$ did not change in group $\mathrm{A}$ while in groups $\mathrm{B}$ and $\mathrm{C}$ there was a further fall so that both, although not significantly different from one another, were significantly better than group $\mathrm{A}$ with levels of $10.3 \pm 0.7 \%$ in group $\mathrm{B}(p<0.05$ compared to $\mathrm{A})$ and $9.4 \pm 0.5 \%$ in group $\mathrm{C}(p<0.002$ compared to A). After 6 months follow-up $\mathrm{HbA}_{1}$ in group $\mathrm{A}$ rose to $12.5 \pm$ $0.3 \%$, a value not significantly lower than the starting level. However, group B maintained their improved control so that 12 months after the beginning of the study their mean $\mathrm{HbA}_{1}$ was $9.5 \pm 0.4 \%$ significantly lower than group $\mathrm{A}(p<0.002)$. Group $\mathrm{C}$, having shown better control during the first intervention period, deteriorated over the 4 months of the second intervention after introduction of the high fibre, high carbohydrate diet so that at the end of the second intervention period their $\mathrm{HbA}_{1}$ was $11.2 \pm 0.5 \%$ compared with $9.4 \pm 0.5 \%$ at the end of the first intervention $(p<0.01)$. However, over the remaining 6 months $\mathrm{HbA}_{1}$ in group $\mathrm{C}$ fell again to $10.0 \pm 0.6 \%$ which was significantly lower than group $\mathrm{A}(p<0.02)$ but no different from group B.

\section{Discussion}

As reported alsewhere [5] this study has shown that imaginative teaching methods can improve dietary knowledge, compliance and metabolic control even in adults with longstanding Type 1 diabetes. The improvement in group B was substantial, achieved using simple dietary advice and was maintained for 6 months after the end of formal educational visits to the doctor and dietician. The increased dietary knowledge and improved day-to- 
day consistency in eating patterns of groups B and C at the end of the first intervention period was also well maintained 6 months later. Thus, although practical lunchtime demonstrations or video tape èducation may be more time consuming than conventional instruction by a dietician, they were in our hands much more effective in changing eating habits and they were also cost effective in that the effects were long lasting.

It has been said [10] that the new dietary recommendations of the British Diabetic Association are in line with the principles of healthy eating advocated for the whole population. However, it remains to be demonstrated whether it is possible to change the eating habits of the general population in such a substantial way and whether they will benefit from the change. In the present study we were able to make modest alterations in the diet of patients in group $\mathrm{C}$ and these were well maintained 6 months later. The change from $42.6 \%$ fat / $38.8 \%$ carbohydrate to $33.9 \%$ fat / $44 \%$ carbohydrate and from 20.3 to $31.0 \mathrm{~g}$ fibre / day is relatively small although statistically significant. However, one should remember that patients in this study had an average duration of diabetes of 11 years and had been selected because of poor metabolic control. During the first intervention period they had been asked to pay much more attention to their eating habits than hitherto with the only concession being that they could continue to eat the kind of food they enjoyed. It may have been expecting too much to ask them in addition to change the type of food as was done during the second intervention. Most were prepared to make modest changes but would not "train" themselves or other members of their family to eat unfamiliar foods. We doubt whether such conservatism is confined to Nottingham.

Although disappointing, it is perhaps not surprising that metabolic control did not improve in group $\mathrm{C}$ while taking the high carbohydrate / high fibre diet given the modest changes in carbohydrate and fibre consumption which we achieved. Previous studies showing a beneficial effect on glycaemic control in insulin treated subjects have prescribed $60-70 \%$ carbohydrate and $65-105$ g fibre daily $[11,12]$ with a substantial proportion of the fibre from legumes and pulses. Unfortunately our patients were unable, or unwilling to make dietary changes of such magnitude. It is hard to explain however why diabetic control actually deteriorated in group $\mathrm{C}$ during the second intervention. Insulin doses and regimens did not change significantly and patients continued to adjust their insulin appropriately on the basis of blood glucose tests. Daily intake of calories was reduced, although not significantly, from $2114 \mathrm{kcal}$ at the end of the first intervention to $1920 \mathrm{kcal}$ at the end of the second. Since patients in group $\mathrm{C}$ were advised to eat fruit liberally it is possible that the extra oligosaccharides consumed might explain their transient worsening of metabolic control. However the extent to which they actually changed their fruit intake (Table 3) makes this unlikely. Alternatively it may be that patients in group $\mathrm{C}$ had reached a point where they were being swamped with so many new changes to their eating habits that they 'gave up' and became less compliant. A third possibility is that they needed longer than four months to adapt to and learn the new diet. Whatever the explanation, one has to conclude that our attempts to implement the new high carbohydrate / high fibre / low fat recommendations [6] had no beneficial effects on metabolic control over and above that achieved by a simple diet concentrating only on the day-to-day concistency of carbohydrate intake.

The gulf between theory and practice of diet treatment in insulin dependent diabetes remains wide. This study has highlighted several practical problems which need to be overcome if we are to persuade our patients to eat healthier diets in the future.

Acknowledgements. This study was supported by a British Diabetic Association development project grant. DKMcC was a research fellow funded by the British Diabetic Association.

\section{References}

1. Williams TF, Anderson E, Watkins JD, Coyle V (1967) Dietary errors made at home by patients with diabetes. J Am Diet Assoc 51: 19-25

2. Tunbridge RE, Wetherill JH (1970) Reliability and cost of diabetic diets. Br Med J 2: 78-80

3. West KM (1973) Diet therapy of diabetes: an analysis of failure. Am Int Med 79: 425-34

4. McCulloch DK, Young RJ, Steel JM, Wilson EM, Prescott RJ, Duncan LJP (1983) Dietary compliance and metabolic control in insulin-dependent diabetics. Hum Nutr: App Nutr 37 A: 287-92

5. McCulloch DK, Mitchell RD, Ambler J, Tattersall RB (1983) Influence of imginative teaching of diet on compliance and metabolic control in insulin-dependent diabetes. Br Med J 2: 1858-61

6. Dietary recommendation for diabetes for the 1980 's - a statement by the British Diabetic Association (1982) Hum Nutr Appl Nutr 36 A: 378-94

7. Metcalfe J (1981) British Diabetic Association. Better cookery for diabetics. Oxley Press, Nottingham

8. Mann J, Oxford Dietetic Group (1982) The diabetic's diet book a new high fibre eating programme. Dunitz, London

9. Ambler J, Walker G, Jamik B (1983) Measurement of glycosylated haemoglobin on cellulose acetate membrane. Clin Chem 29: 340-3

10. Thomas BJ (1983) New facets of diabetic diets. J Royal Coll Physicians Lond 17: 188-191

11. Anderson JW, Ward K (1979) High carbohydrate, high fiber diets for insulin-treated men with diabetes mellitus. Am J Clin Nutr 32: 2312-21

12. Simpson HCR, Lousley S, Geekie M, Simpson RW, Carter RD, Hockaday TDR, Mann JI (1981) A high carbohydrate leguminous fibre diet improves all aspects of diabetic control. Lancet 1:1-5

Received: 20 August 1984

and in revised form: 2 March 1985

Dr. R. B. Tattersall

University Hospital

Queens Medical Centre

Nottingham NG7 2UH

UK 